\title{
The Path for Cultivation of College Students' Comprehensive Quality from the Perspective of General Education
}

\author{
Dong Long \\ Zhuhai College of Jilin University \\ Zhuhai, China \\ School of Marxism Studies \\ Nanjing University of Science \&Technology \\ Nanjing, China 210094
}

\begin{abstract}
The "13th Five-Year Plan for the Development of National Education" puts forward the "exploration of the general education and professional education combined talent cultivation method" which once again makes clear the future development direction of general education in higher education. From the perspective of general education, the cultivation of college students' comprehensive quality under the guidance of professional education thoughts will face new challenges. General education aims to cultivate students to form more complete personality, broader knowledge, more solid ability and broader vision. The basic path for future development of general education and cultivation of college students' comprehensive quality is to build the concept of cultivating people by general education in colleges and universities, make clear the core elements of college students' comprehensive quality cultivation, set up general education course with Chinese historical and cultural characteristics, create a campus culture brand in line with the needs of students, and improve the colorful study travel program.
\end{abstract}

Keywords-general education; college students' comprehensive quality; historical and cultural characteristics; campus culture brand; study travel

\section{INTRODUCTION}

The "13th Five-Year Plan for the Development of National Education" puts forward the "exploration of the general education and professional education combined talent cultivation method" which once again makes clear the future development direction of general education in higher education. As a kind of education method and concept different from professional education, general education plays a unique role in promoting the development of comprehensive quality of college students. However, under the guidance of professional education thoughts, the comprehensive quality cultivation of college students is in face of challenge of the reality. In the process of receiving higher education, many college students have limited personality shaping degree, insufficient knowledge breadth, insufficient practical ability, and narrow external vision. Those status quo are not conducive to the overall quality cultivation of college students so that higher education fails to give full play its role and function in cultivating talents. In terms of future higher education development in China, it is necessary to vigorously promote conditioned colleges to carry out general education, enrich the forms of genera education, play the role of general education in improving students' personality, expanding students' knowledge, exercising students' ability and broadening students' horizons, and practically improve the comprehensive quality of college students on the basis of the current situation of comprehensive quality cultivation of college students.

\section{CONNOTATION OF GENERAL EDUCATION}

General education is the product of the development of modern higher education in Europe and America and is a new educational concept. In recent years, with the rise of globalization, general education has gradually become the focus of attention in the field of higher education. However, there is still no complete consensus on the connotation of general education in theoretical circle. Foreign scholars generally believe that the core of general education is freedom education or liberal arts education and is to inherit the traditions of freedom and humanities. Chinese scholars understand general education from a single dimension (purpose, requirements, content, etc.) or explain it from multiple interrelated levels or aspects. [1] Although Chinese and foreign experts and scholars have different definitions on the connotation of general education, most of them agree that general education is not a simple educational method and content, but a unique education concept aiming at cultivating students' sound personality and good virtues and promoting their all-round development. [2]

The concept of general education comes from a perfect combination of European freedom education and liberal arts education; although it is originated from Europe, it is actually formed in the United States; namely, it was gradually formed with the rise of the reform wave in American universities at the end of the 19th century. In ancient China, many educational ideas had contained the connotation of general education. They not only explained the purpose of general education, but also made clear the 
content of general education. Confucianism in ancient China emphasized narration, art, and rhetoric. It drawn on the essence of classics and the strengths of various scholars, getting ancient and current features integrated. Confucians should not only have extensive knowledge reserves and superb rhetoric skills, but also adhere to traditional beliefs and orthodox way. The two-dimensional structure of "liberal arts" is the overall framework of gentleman personality as advocated by Confucians; meanwhile, the spirit of "liberal arts" also becomes the core connotation of Confucian educational thought. For another example, the early education of "Six Arts" of Confucianism had included the content of general education. "Six Arts" was the basic skills such as ritual, music, archery, charioteering, calligraphy, and mathematics to be master by students. Since the new century, general education has received much attention and its concept begun to positively influence the talent cultivation mode in Chinese colleges and universities. Many colleges and universities have actively promoted the reform and innovation of education and teaching by strengthening general education. Followed by, a number of colleges and universities have successively established general education colleges, such as Yuanpei College of Peking University, Chu Kochen Honors College of Zhejiang University, Fudan College of Fudan University, Kuang Yaming Honors School of Nanjing University, Boya (Liberal Arts) College of Sun Yat-sen University, and QianWeichang College of Shanghai University. General education has started a new stage of development in China.

Mou Zongsan holds that "general education is not to get one acquired a lot... the most basic purpose and spirit of general education is to let one or learner know himself and the times." China is in the new era of socialism development. The connotation of general education should conform to the inherent requirements of China's social and cultural development and meet the needs of the construction of socialism with Chinese characteristics in the new era. General education is a combination of educational concept and educational practice, aiming at cultivating students' sound personality, extensive knowledge, solid ability and broad vision. On this basis, only by further clarifying the educational concept and cultivation objectives of general education can it be available to truly promote the transformation of talent cultivation model, drive the comprehensive development of students' comprehensive quality, and boost the future development of higher education.

\section{THE ESSENTIAL REQUIREMENTS OF GENERAL EDUCATION AND THE STATUS QUO OF COMPREHENSIVE QuAlity CULTIVATION OF COLLEGE STUDENTS}

The ultimate goal of education is to cultivate people. Cultivating people into which kind of talents becomes the starting point and foothold of education. The "13th FiveYear Plan for the Development of National Education" puts forward the "exploration of the general education and professional education combined talent cultivation method" which clarifies the contemporary talent cultivation goals and methods. With the increasingly fierce competition in Chinese society and the increasingly severe employment situation, the society and employers have higher positioning of talent criteria, and composite talents are favored. The comprehensive quality of talents will become the focus of consideration of employers. As an education for comprehensive development-based talent cultivation, general education plays an important role in the cultivation and promotion of the comprehensive quality of college students.

\section{A. Essential Requirements of General Education}

As an education for comprehensive development-based talent cultivation, general education aims at cultivating people's all-round quality. The cultivation and development of college students' comprehensive qualities such as morality, intelligence, physique and aesthetics cannot be separated from general education. General education aims to cultivate students to form more complete personality, broader knowledge, more solid ability and broader vision. Therefore, the essential requirement of general education is to cultivate students' comprehensive qualities such as personality, knowledge and ability, help them form sound personality, acquire extensive knowledge and comprehensive ability, broaden their external visions, and to enable students to develop in an all-round way. This is also the basic requirements for the development of comprehensive quality of contemporary college students. [3] The requirements of general education for comprehensive quality of college students are mainly reflected in the status quo of their knowledge learning, ability practicing and personality shaping.

\section{B. Current Status of Comprehensive Quality Cultivation of College Students}

Under the guidance of professional education thoughts, the comprehensive quality cultivation of college students is in face of challenges of the reality which are reflected in the limited personality shaping degree, insufficient knowledge breadth, insufficient practical ability, and narrow external vision. Those are all side reflections of the current status of comprehensive quality cultivation of college students.

1) Limited personality shaping degree: Having a sound personality is a basic requirement for college students to have a strong overall quality. Excessive professional education emphasizes the imparting of knowledge, and is easy to neglect the shaping of students' personality, so that it is difficult for many college students to effectively shape their own personality while receiving higher education in school time. Personality shaping is reflected in guiding college students' self-living habits, practicing their independent living ability, and helping them shaping a correct understanding of the relationship between people, between people and society, and between people and nature around their lives. [4] After entering university, the values and lifestyles of college students have undergone fundamental changes. At present, the personality shaping degree of college students is very limited, which makes it difficult for many college students to develop good habits and acquire independent living ability; excessive consumerism becomes prominent; they often have difficulty 
in understanding the existence of self, society and nature and even have a recognition in contrary to common sense, which directly affects their ability to adapt to self, society and nature and is not conducive to the comprehensive development of their comprehensive quality in the future.

2) Insufficient knowledge breadth: Professional education focuses on cultivating students' professionalism, training students' professional ability, and imparting students' professional knowledge. Too narrow professional education emphasizes much on the imparting of professional knowledge to students, and guides students to pay too much attention to their professional knowledge, while ignoring general knowledge that is important for future development; hence, there is a situation of insufficient knowledge breadth. In the study in university, students over-emphasize the study of professional knowledge, while ignoring the knowing and learning of knowledge outside the major or the crossdisciplinary field. The knowledge acquired is not rich and comprehensive enough, and cannot fully meet the requirements of modern society for knowledge reserves; at the same time, many college students lack historical and cultural knowledge, know little about Chinese and the world's history and culture, lack the necessary knowledge support for inheriting, disseminating and carrying forward Chinese traditional culture, have not that clear understanding of historical and cultural values, and are difficulty to have a forward-looking view or understanding of the formation of China's general trend and the global situation. [5]

3) Insufficient practical ability: Practice ability is a core component of the comprehensive quality of students. Chinese universities have always had a tradition of attaching importance to knowledge transfer and ignoring capacity cultivation. Despite the continuous advancement and development of market economy, students' practical ability has been greatly improved; to a certain extent, they can adapt to the changing development needs of the society; but there are still considerable number of college students who have insufficient practical skills and capabilities. This is inseparable from the existing educational concepts and models which overemphasize the importance of knowledge acquisition and neglect the cultivation and training of students' practical ability, forming unhealthy guidance for students so that many students to focus on knowledge learning while ignoring the cultivation of such abilities as critical thinking, innovative thinking, interpersonal communication, expression writing, collaborative work, etc.; the lack of those practical abilities is difficult to show its importance during school time, but will become a barrier when students go out of school, entering the society, especially in the face of employment so that they cannot take the priority in employment or future development.

4) Narrow external vision: Study in university is more to better know about and understand the society and the world we live in through the experience in university. It is undeniable that many of college students have improved and broadened their external visions in school time by means of contacting with new schoolmates, new teachers, new ways of learning, new cities, new environments, and new lifestyles. However, there are also quite a number of students who fail to achieve the external vision degree as expected and go to a narrow side instead. Students often pay excessive attention to the small circle of their lives, lack necessary experience and vision of the society and world outside school and lack necessary understanding and mastering of the big development trend and situation of China and the world except knowing certain affairs within their university, so that they cannot well analyze the era in which they live and well grasp the opportunities and chances for future vocational development. The narrow vision limits many college students' work creativity and future ability to make achievement.

\section{The Necessity for Cultivating College Students' Comprehensive Quality from the Perspective of General Education}

General education requires shaping a fully developed person and cultivating and developing the comprehensive quality of students. However, the status quo of comprehensive quality development of college students is worrying. Judging from the current situation of knowledge learning, ability practicing and personality shaping of college students, there is a large gap between their development status and requirements of general education. The contradiction between the two lies in the serious disconnection between the requirement and the reality. That is to say, in the process of education implementation, due to many obstacles, it is hard for college students' comprehensive quality development to keep in line with the requirement of general education. Those obstacles not only include the factors in general education itself, such as the lack of general education awareness and the lack of general education practice, but also include social factors, such as the negative influence of some bad social ideological trends and negative guidance of excessive competition on the comprehensive quality cultivation of college students. To resolve the contradiction, it is needed to further reform the educational concepts and methods.

The development of comprehensive quality of college students is inseparable from general education. As general education plays an increasingly important role in the field of higher education, professional education is no longer dominant and the cultivation and development of comprehensive quality of college students are widely concerned by all circles in the society. Professor Chen Xiangming believes that general education aims to cultivate high-quality talents who have a relatively broad professional knowledge and abilities and have somewhat understanding of the main knowledge areas of human; however, the goal of professional education is to cultivate senior professionals having profound knowledge and abilities in a particular field of expertise". [6] Compared with professional education, general education has three advantages in cultivating comprehensive quality of college students: first, through the 
study of extensive knowledge, college students can have richer knowledge reserves, more diverse ways of thinking, and more intense awareness of problems; second, through the training of their own abilities, their adaptability, problemsolving ability and creativity can all be well developed and improved; third, in the process of cultivating a healthy personality, students can shape in to "true man" by embodying the value of people on the people-oriented principle and gradually guiding them to pursue for the values of self and life.

\section{BASIC PATH FOR CUltivation OF COLlEGE STUDENTS' COMPREHENSIVE QUALITY}

The cultivation of college students' comprehensive quality is a key point that cannot be ignored in the field of higher education, and is also a problem necessary to be solved for steady development of general education. From the perspective of general education, the basic path of the comprehensive quality cultivation of college students includes the following points: first, starting from the theory, establishing the basic concept of talent cultivation by general education in colleges and universities; second, making clear the core elements of the comprehensive quality cultivation of college students on the basis of the development of the times; third, carrying forward excellent Chinese culture and setting up general education course with Chinese historical and cultural characteristics; fourth, creating a campus culture brand in line with students' development demands on the basis of the characteristics of colleges and universities; fifth, meeting the needs of students and improving the colorful full-process study travel program.

\section{A. Establishing the Basic Concept of Cultivating Talents by General Education in Colleges and Universities}

At present, there is certain difference between general education and cultivation of comprehensive quality of talents in colleges and universities. Hence, it is especially important to establish the basic concept of cultivating talents by general education in colleges and universities. Colleges and universities should closely follow the essential requirements of general education, establish the basic concept of cultivating talents by general education in colleges and universities, and provide students with diverse learning and all-round development conditions, so that students have diversified development space and all-round development prospect. To establish the basic concept, the following three points should be followed: first, universities should pay attention to the shaping of healthy personality of college students, give play to the cultural inheritance role of general education, stimulate excellent quality of students, promote the building of their outlooks of the world, life and value, and guide them to develop towards a sound personality with "integration of knowledge and action"; second, knowledge characteristics of general education should be reflected in the knowledge acquisition of college students, namely not only have the most basic stability of knowledge, but also be holistic, both pay attention to rational construction of knowledge to realize progressive and remedial imparting of knowledge and give the knowledge a certain degree of broadness and diversity; [7] third, colleges and universities should pay attention to students' comprehensive ability practicing. Comprehensive ability is an important manifestation of general education. The improvement of students' comprehensive ability will also make their learning and life more efficient.

\section{B. Making Clear the Core Elements of the Comprehensive Quality Cultivation of College Students}

China has entered a new era of socialism; higher education is going to enter the stage of popularization; the cultivation of comprehensive quality of college students should not be ignored as they shoulder the great historical mission of the era and are the major participants in higher education. While practicing the concept of general education, colleges and universities must also clarify the core elements of college students' comprehensive quality. The core elements should include sound personality, broad knowledge, solid ability and broad vision. Taking the core elements as the guide for talent cultivation, colleges and universities should provide targeted guidance from different aspects, guide students to consciously cultivate and improve their self-comprehensive qualities, help students to build an independent learning system so that students can accumulate knowledge practice their abilities, and learn to make selfplanning and development, form positive individual quality in their independent learning process, to further lay a solid foundation for innovation and entrepreneurship [7] and make contribution to the society.

\section{Setting up General Education Course with Chinese Historical and Cultural Characteristics}

A general education course with Chinese historical and cultural characteristics is a necessary prerequisite for carrying out general education with Chinese characteristics. China has a profound history and culture. Carrying out Chinese history and culture curriculum education will help to spread Chinese excellent traditional history and culture, enhance students' cultural accomplishment, strengthen students' cultural accomplishment from the foundation, improve their quality of humanities, and promote their sound development of comprehensive quality. From the perspective of cultivating the comprehensive quality of college students, colleges and universities should focus on the development of general education courses with Chinese historical and cultural characteristics, break the barriers between disciplines based on the real conditions of students, and open a general education course on Chinese history and culture in a wider scope and create new way of classroom; this way is to strengthen the sense of participation of students, let students understand the changes of Chinese history and culture in an all-round, multi-angle and three-dimensional way and the future development trend, truly enhance their cultural confidence, let students constantly improve their humanistic quality and cultural accomplishment while internalizing Chinese excellent history and culture, and further promote the development of their comprehensive quality in a point-to-face manner. 


\section{Creating a Campus Culture Brand in Compliance with Students' Development Demands}

Campus cultural activity is the important base of university education and teaching and also an important part of general education. At present, the first classroom in colleges and universities lacks the characteristics of general education so that it has little effect on stimulating students' personality building, knowledge learning, ability practicing, vision broadening, as well as their enthusiasm and positivity to learn and only makes limited contribution to cultivate students' comprehensive quality. Creating campus culture brand activities in line with students' development demands is the basic performance in doing well a second classroom. In this way, students can cultivate their taste, improve their abilities, broaden their visions, adapt to the social demand in rich and colorful campus cultural activities; this way can also vigorously support rooting the concept of general education in colleges and universities, and service the demand for reaching the learning-based innovative and composite talent cultivation objective. To build a brand of campus culture, school should provide better learning opportunities on the basis of understanding the development demands and interests of common students, reduce professional restrictions, and enrich the forms and types of activities. Next, the building of this brand should keep in pace with the social development and constantly make improvement and never stop. Colleges and universities should make clear the core concept of running the school, determine the cultural theme and educational brand of the school, and create a good campus learning atmosphere, so that students can cultivate their sentiments and strengthen their own cultural accomplishment. Finally, school should actively develop school-based curriculum, highlight the cultural characteristics of the school, create a brand of campus culture, constantly deepen classroom reform, and improve the accuracy and richness of knowledge.

\section{E. Improving the Colorful Full-process Study Travel Program}

The unity of knowledge and action is what university education pursues and what general education has always advocated. It can not only cultivate students' ability to learn knowledge, but more enable students to be inspired and acquire knowledge practically. Study travel combines "learning" and "doing" together and has three characteristics such as nature, experience and curriculum. [8] Study travel is a powerful complement to existing university education and teaching mode. Under the guidance of the concept of talent cultivation by general education, school should actively organize students to carry out various forms and levels of "study travel" plan for the purpose of cultivating college students' external vision, enriching their experiences and improving their comprehensive quality; this way can help students to get out of the campus, contact with more fresh external affairs, know more about the ongoing changes of the outside world, master the latest science and technology and humanity knowledge, and further broaden their vision, let them experience different culture and enrich their knowledge while improving their cultural accomplishment. Therefore, school should develop a variety of study travels, and make full-process learning plan, so that students can gradually accumulate cultural accomplishment step by step.

\section{CONCLUSION}

To sum up, from the perspective of general education, it is concluded that the cultivation of college students' comprehensive quality under the guidance of professional education thoughts will face new challenges. General education aims to cultivate students to form more complete personality, broader knowledge, more solid ability and broader vision. With respect to future development of general education and cultivation of college students' comprehensive quality, the basic path is to establish a concept of cultivating people by general education in colleges and universities, make clear the core elements in cultivating college students' comprehensive quality, set up general education curriculum with Chinese historical and cultural characteristics, create a campus culture brand in line with the needs of students, and improve the colorful study travel program.

\section{REFERENCES}

[1] Zhang Liping. Research on General Education in Chinese Universities from the Perspective of Globalization [D]. Wuhan University, 2014. (in Chinese)

[2] Li Yurong, Li Huijing. Analysis of the Ways to Cultivate College Students' Competitive Ability Based on the Competency Model [J]. Heilongjiang Researches on Higher Education, 2015(9):141-144. (in Chinese)

[3] Tang Dan, Wu Manyun. Research on the Innovation of College Students' Ideological and Political Education from the Perspective of "Weibo, WeChat, News App" [J]. Media, 2017(24): 83-85. (in Chinese)

[4] Wang Jie, Jiang Canhua. The Cultivation of College Students Autonomous Learning Ability and Comprehensive Quality against the Background of Innovation and Entrepreneurship [J]. Higher Education Exploration. 2016 (11):117-120. (in Chinese)

[5] Ma Zaoming, Gao Huangwei. On the Evolution and Transformation of Value Orientations of General Education in Universities [J]. Educational Research, 2016(4): 52-60. (in Chinese)

[6] Wang He. The Way to Build University Students' Growth Display Platform [J]. Chinese University Science \& Technology, 2015(12): 86-87. (in Chinese)

[7] Mao Kaiyi. Principle and Criteria for the Evaluation of College Student Community from the Perspective of Quality Education [J] Heilongiiang Researches on Higher Education, 2017(5): 79-81. (in Chinese)

[8] Chen Miao. A Probe into the Status of Communist Youth League Work in University and the Path in the Context of UniversityEnterprise Cooperation [J]. Theory and Practice of Education, 2017(30): 29-30. (in Chinese) 